\title{
Food allergy management from the perspective of patients, caregivers and allergists: a qualitative study
}

\author{
Ya S Xu ${ }^{1 *}$, Susan Waserman ${ }^{2}$, Lori Connors ${ }^{2}$, Kristin Stawiarski ${ }^{3}$, Monika Kastner $^{4}$ \\ From Canadian Society of Allergy and Clinical Immunology Annual Scientific Meeting 2010 \\ Victoria, Canada. 3-6 November 2010
}

\section{Background}

Long term management of food allergy is subopti$\mathrm{mal}^{1,2,3}$. Our study aims to provide direction for improvement, by evaluating the current state of food allergy management from the perspective of allergists, food allergic patients or their caregivers in outpatient settings in Ontario.

\section{Materials and methods}

This two-part study included an questionnaire completed by food allergic families to explore what information they received on food allergy, their confidence around self-management, and their learning needs; and a qualitative interview with allergists to explore their perception of teaching priorities, and the challenges and strategies in food allergy management. Using convenience sampling, participants were recruited from allergy clinics across Ontario. Analyses included descriptive statistics and frequency analysis (quantitative data) and grounded theory methodology (qualitative data) ${ }^{4,5}$.

\section{Results}

Six allergists and 92 of their food allergic families, from Toronto, Hamilton, London, Kitchener, and Kingston, participated. Key areas requiring improvement in food allergy management were identified from the survey: $33 \%$ of families were not shown how to use an epinephrine auto injector with a trainer, $57 \%$ were asked to demonstrate its use with an auto injector despite being on average at their 5 th visit, and 30\% felt confident about when and how to administer an auto-injector. Many newly diagnosed families did not receive sufficient information during the visit, including medic alert identification

\footnotetext{
* Correspondence: Sophia.xu@medportal.ca

'Department of Pediatrics, McMaster University, Hamilton, Ontario, L8N 3Z5, Canada

Full list of author information is available at the end of the article
}

(50\%) and information about support groups (21\%). Interviews with allergists indicated that a key challenge was limitation in time and nursing resource.

\section{Conclusions}

Our study highlights the experiences and educational needs of 92 food allergic families in Ontario, and the challenges faced by the 6 allergists managing them. Identified gaps could be addressed through the provision of practice sessions with an auto-injector training device; and developing training materials to simulate anaphylactic reactions, which may improve patients' confidence in self management.

\section{Author details}

${ }^{1}$ Department of Pediatrics, McMaster University, Hamilton, Ontario, L8N 3Z5, Canada. ${ }^{2}$ Department of Medicine, McMaster University, Hamilton, Ontario, L8N 3Z5, Canada. ${ }^{3}$ Bachelor of Health Sciences Program, Faculty of Health Sciences, McMaster University, Hamilton, Ontario, L8N 375, Canada.

${ }^{4}$ Department of Clinical Epidemiology and Biostatistics, McMaster University, Hamilton, Ontario, L8N 3Z5, Canada.

Published: 4 November 2010

\section{References}

1. Al-Matar $\mathrm{H}$, Sussman GL: Use assessment of self-administered epinephrine devices among patients with anaphylactic reactions. Can J Allergy Clin Immunol 2001, 6:8-9.

2. Bock SA, Muñoz-Furlong A, Sampson HA: Further fatalities caused by anaphylactic reactions to food, 2001-2006. J Allergy Clin Immunol 2007, 119(4):1016-8.

3. Kastner M, Harada L, Waserman S: Gaps in anaphylaxis management at the level of physicians, patients, and the community: a systematic review of the literature. Allergy 2010, 65:435-444.

4. Patton MQ: Qualitative Research and Evaluation Methods. California: Sage Publications Inc. 2002, 3.

5. Strauss ACJ: Basics of qualitative research: grounded theory procedures and techniques. California: Sage Publications Inc. 1990.

doi:10.1186/1710-1492-6-S2-P8

Cite this article as: Xu et al:: Food allergy management from the perspective of patients, caregivers and allergists: a qualitative study . Allergy, Asthma \& Clinical Immunology 2010 6(Suppl 2):P8. 